\title{
An update on the role of prokineticins in human reproduction-potential therapeutic implications
}

\author{
Kulvinder Kochar Kaur ${ }^{1 *}$, Gautam Allahbadia ${ }^{2}$, Mandeep Singh ${ }^{3}$ \\ ${ }^{1}$ Dr Kulvinder Kaur Centre for Human Reproduction, Jalandhar, India \\ ${ }^{2}$ Rotunda-A Centre for Human Reproduction, Mumbai, India \\ ${ }^{3}$ Swami Satyanand Hospital, Jalandhar, India \\ Email: ${ }^{*}$ kulvinder.dr@gmail.com, drallah@gmail.com, gundeep26@hotmail.com
}

Received 8 July2013; revised 5 August 2013; accepted 13 August 2013

Copyright (C) 2013 Kulvinder Kochar Kaur et al. This is an open access article distributed under the Creative Commons Attribution License, which permits unrestricted use, distribution, and reproduction in any medium, provided the original work is properly cited.

\begin{abstract}
Objective: Prokineticin-1 (PROK1) is a recently described protein with a wide range of functions including tissue specific angiogenesis, modulation of inflammatory responses and regulation of haematopoiesis. PROK1 has been found in the steroidogenic organs like ovary, testis, adrenal and specially placenta and they have been found to have a role in development of the olfactory system and GnRH system. The aim was to update the role of PROK1 and PROK2 in human reproduction since the review was provided by Maldono-Perez (2007) on the potentials of prokineticins in reproduction. Design: A review of international scientific literature by a search of Pubmed and the authors files was done for citation of articles relevant to prokineticins in reproduction, be it its role in ovary, testis, uterus with special emphasis on implantation, normal pregnancy, in labour, pathophysiological states like tubal pregnancy, pcos, various genital tumours, and cases of isolated hypogonadotropic hypogonadism with mutations with PROK2/ PROKR2 and studies detailing functional mechanisms. Results: In the normal cycle, PROK1 has been found to have important roles in implantation, regulating several genes like COX-2, IL-8, IL-11, CTGF related to implantation. Initially murine studies revealed a critical role of PROK2 pathway on olfactory bulb morphogenesis and GnRH secretion which was accidentally discovered and since then several studies on mutations in PROK2/PROKR2 showed that they underlie some case of $\mathrm{KS}$ in humans. Although in mouse heterozygote state is not associated with clinical phenotype, most of human mutations are heterozygous. Conclusions: Role of PROK-1 in the process of implantation, with a deeper understanding
\end{abstract}

${ }^{*}$ Corresponding author. of the process success rates in IVF and ART can be improved, besides understanding the pathophysiology of tubal pregnancy. Further presence in ovarian follicles of PROK1 can be used to plan a strategy for treating pcos. Development of antagonism of PROK'S may be a helpful strategy in treating preterm labour.

Keywords: Prokineticin 1; Prokineticin Receptor 2; Kallmanns Syndrome; Implantation;

GnRH Development

\section{INTRODUCTION}

The prokineticins (PROK) are a family of two multifunctional secreted proteins called prokineticin 1 (PROK1) [1] and PROK2, alias Bombina variegate $8(\mathrm{Bv} 8)$ [2]. The names PROK1 and PROK2 were assigned to these proteins by Li et al. to reflect their functions in inducing specific and potent contractions of the gastrointestinal tract (GIT). Le Courtier et al. described a growth factor which induced strong and reproducible mitogenic response in endocrine gland-derived endothelial cells [3]. A similar effect induced by this protein and by vascular endothelial growth factor (VEGF) lead it to be named endocrine gland VEGF (EG-VEGF) [4]. The two proteins are structurally unrelated despite several similarities in the function and control mechanisms.

The gene that encodes human PROK1 is located on chromosome 1 (1p.13.3) and is encoded by three exons. The mature human PROK1 peptide consists of 86 amino acids. The most active PROK2 peptide consists of 81 amino acids and is encoded by a four-exon gene on chromosome 3 (3p21.1). The additional exon of PROK2 gene can be actively spliced resulting in longer isoform PROK2 L (102 amino acids) whose function is not well understood [5]. The PROK have been shown to regulate 
Angiogenesis [6], neuron genesis [7], pain sensation [8] intestinal contraction [1], haematopoiesis [4], immune response [9] and reproduction [10].

PROK bind to two closely related G-protein coupled receptors (GPCR) known as prokineticin receptor1 (PROKR1) and PROKR2; with both receptors being able to bind PROK1 and PROK2 with similar affinities [11]. Mature PROK1 and PROK2 are ligands for the highly homologous (85\%) GPCR, (PROKR1 and PROKR 2 formerly known as GPR73a and GPR73b respectively). In contrast to high homology exhibited by PROK recaptors, the ligands PROK1 and PROK2 share only 44\% aminoacid identity. Respecting the conserved N terminal AVITGA sequence Kaser et al. (2003) proposed the term AVIT family to classify the prokineticins and their nonmammalian orthologs [12]. Despite only $45 \%$ homology PROK1 and PROK2 share two conserved feautures during molecular evolution essential for bioactivity, 1) a highly conserved hexapeptide AVITGA sequence and 2) their $\mathrm{N}$ terminal and a distinctive structural motif consisting of ten cysteine residues with five disulphide crosslinking. The striking differential expression in prokineticins results in PROK1 being predominately expressed in steroidogenic endocrine cells [3], while PROK2 is mainly expressed in nonsteroidogenic cells of the testis and the central nervous system.

\section{PROKINETICINS IN FEMALE REPRODUCTIVE FUNCTION}

Ovary: Prokineticin 1 (PROK1) is expressed in a dynamic way in elements of sex-cord stromal lineage [13], whereas prokineticin 2 (PROK2) expression is undetectable [14]. During follicle maturation, PROK1 and vasculal endothelial growth factor (VEGF) expression are inversely related. In primordial and primary follicles, there is a high expression of PROK1 in granulosa cells but no VEGF expression. 1) Maturing secondary follicles maintain strong PROK1 expression and weak to moderate VEGF expression. 2) In contrast, in the antral follicles PROK1 is expressed at low levels in theca cells, whereas VEGF expression is very strong in granulosa cells and moderate in theca cells. 3) In the mature atretic follicle PROK1 expression is strong again in residual theca and VEGF expression is weak. The high expression of PROK1 in atretic follicles might relate to hypoxia (via HIF- $\alpha$ ) secondary to regressive/apoptotic changes occurring in these follicles and serves as a signal for remodeling. 4) In the corpus luteum (CL) the mRNA expression of PROK1 increases as the CL matures, whereas VEGF expression is already maximal at the early luteal phase $[14,15]$. These differential expression patterns suggest that VEGF and PROK1 have different roles in the vascular and nonvascular structures in the CL. The actions of PROK1 in the ovary are likely to be me- diated by PROKR1 and PROKR2 which are expressed in the ovary $[11,16]$. However their precise localization has not yet been elucidated. Studies in vitro suggest that PROK1 has a role in the proliferation and survival of endothelial cells of bovine corpus luteum [17]. An indirect role for angiogenesis in the CL also has been suggested following the observations that PROK1 can stimulate the expression of VEGF $[18,19]$.

Practical Implications: Ferrara et al. 2003 studying 13 PCOS human ovaries in comparison to 13 normal ones found a particular high expression of PROK1 in the Leydig like hilus cells found in the highly vascularized ovarian hilus. In PCOS ovaries they found strong expression of PROK1 mRNA in theca interna and stroma, which are spatially related to new blood vessel. In contrast VEGF mRNA expression was most consistently associated with the granulosa cell layer and sometimes the theca, but rarely the stroma. These findings of expression of both VEGF and PROK1 expression in PCOS ovaries but in different cell types, at different stages of differentiation, suggested a complementary functions for the two factors in angiogenesis and possibly cyst formation [14].

\section{POTENTIAL ROLE OF PROKINETICINS IN PREGNANCY}

\subsection{Implantation}

PROK1 and PROK2 show differential expression across the menstrual cycle. One of the earliest signs of implantation are hyperaemia and endothelial leakage at the implantation site $[20,21]$. There is increased endometrial expression of PROK1 in the midsecretory phase and both PROK1 and PROKR1 increase in first trimester decidua. PROK1 and PROKR1 immuno localize to stromal endothelial and glandular epithelial cells of the endometrium and smooth muscle and endothelial cells in the myometrium $[22,23]$. Expression of PROK1 has been shown to be highest during the secretory phase of the menstrual cycle, and it has been proposed that its role maybe in vascular differentiation and spiral artery formation during the secretory phase. Also, its presence in myometrial smooth muscle as well as intestinal smooth muscle, suggests that it may also play a role in myometrial contractions [22].

PROK1 but not PROK2, PROKR1, or PROKR2 expression peaks during the midluteal window of implantation. Evans et al. (2008) demonstrated elevated expression of PROK1 and PROKR1 in first trimester deciduas in comparison to nonpregnant endometrium. Expression of both proteins in first trimester deciduas was localized to glandular epithelium and various compartments within the stroma and endothelial cells of the microvasculature. In addition PROK1 but not PROKR1 was detected in 
uterine natural killer cells [23]. Gene array analysis of an endometrial epithelial line stably expressing PROKR1 (PROKR1-Ishikawa) demonstrated, PROK1-PROKR1 signalling regulated genes involved in endometrial receptivity and implantation of early pregnancy. These genes included cyclooxy genase 2 (COX2), laeukemia inhibitory factor (LIF) [23,24], interleukin-8 (IL-8) [25], and interleukin 11 (IL-11). Studies have demonstrated regulation of PROK1 by progesterone $(\mathrm{P})$ and human chorionic gonadotropin (hCG) in the endometrium $[22,24,26]$. Dual immunohistochemical analysis co-localized expression of luteinizing hormone (LH)/hCGreceptor, PROK1, PROKR1 and LIF to the glandular epithelial cells of the first trimester decidual tissue. PROK1 enhances adhesion of trophoblast cells to fibronectin and laminin matrices, which are mediated predominantly via LIF induction. Hence maternal-embryonic crosstalk in which embryonic hCG via endometrial PROK1 may play a pivotal role in enhancing receptivity and maintaining early pregnancy [24]. Further Cook et al. (2010) demonstrated the mechanism by which PROK1 modulated IL-11 expression via a PROKR1 and a calcineurin/nuclear factor of activated T cells (NFAT) signaling pathway, on a calcium, guanine nucleotide binding protein $(\mathrm{Gq} / 11)$ and extracellular signal related kinase (ERK) dependent manner in human endometrium and first trimester deciduas [27]. Overexpression of regulator of calcineurin 1isoform 4 (RCAN 1-4) - a negative regulator of calcineurin signaling leads to a reduction in PROK1 induced IL-11, indicating that RCAN 1 - 4 is acting as a negative regulator of the signaling pathway mediating IL-11. IL-11 is known to be essential for successful decidualization and implantation. In human endometrial stromal cells IL-11 has been shown to advance progesterone induced decidualization implying a role for IL-11 in preparing endometrium for implantation [28]. Relaxin and PGE2 have been shown to increase IL-11 mRNA and protein secretion in decidualized endometrial stromal cells [29]. The same gene array analysis also identified connective tissue growth factor (CTGF) as a target for PROK1 [23]. CTGF is a heparin binding $38 \mathrm{kDa}$ cysteine rich peptide that belongs to the $\mathrm{CCN}$ (Cyr 61, CTGF, Nov) family of secretory proteins, with biological activities related to cellular proliferation, differentiation, adhesion, chemotaxis, migration, apoptosis and extracellular matrix production. It also has a role in regulating implantation and placentation [30,31] with expression being increased from placentae from women with preeclamsia compared with normal pregnancy [32]. CTGF expression was upregulated by PROK1 in early pregnancy decidua via activetion of the Gq, PLC, cSrc, EGFR, MAPK/ERK kinase pathway. Treatment of trophoblast derived HTR-8/Svneo cells with $1 \mu \mathrm{g} / \mathrm{ml}$ CTGF significantly increased adhesion to collagen IV, and differentiation of the cells into tube like structures in matrigel suggesting CTGF may contribute to the regulation of trophoblast conversion of maternal spiral arteries [33]. Mcdonald et al. 2011 showed that PROK1 signalling via PROKR1 regulated Dickkopf 1 (DKK1) expression, a negative regulator of canonical Wnt signaling, and its function in the nonpregnant endometrium and first trimester deciduas [34]. DKK1 mRNA expression is elevated during midsecretory phase of the menstrual cycle and expression increases further in first trimester deciduas. DKK1 protein expression is localized to glandular epithelium and stromal cells during the proliferative, early and secretory phases. However expression is confined to the stroma in the late secretory phase and first trimester deciduas. PROK1 has been shown to regulate the expression of IL- 8 and IL-11 via a Gq-calcium-calcineurin-NFAT signaling pathway. PROK1 induced DKK1 expression in endometrial epithelial cells and decidualizes stromal cells stably expressing PROKR1by same pathway. In this pathway calcium dependent activation of calcineurin causes dephosphorylation of NFAT, allowing it to translocate to the nucleus and activate NFAT regulated gene transcription. The calcineurin-NFAT signaling pathway is regulated by RCAN1-4, an endogenous inhibitor which acts to bind to calcineurin and prevent its activation of NFAT (Figure 1). The study by Mcdonald et al. (2011) confirmed that RCAN1-4 is a negative regulator of PROK1 mediated DKK1 expression in epithelial cells proliferation, and in the decidua it regulate decidualization of the stroma. The calcineurin-NFAT pathway has previously been shown to be involved in regulating endometrial epithelial cell proliferation [35] and endometrial expression of IL-11. DKK1 expression is known to be increased upon decidualization of human endometrial stromal cells (HESC) in culture $[36,37]$, and was demonstrated to be elevated in first trimester decidual tissue where it localizes primarily to the stromal compartment. Recently PROK levels have been shown to increase in stromal cells decidualized in vitro $[38,39]$, and PROK1 is increased in decidualized tissue [23]. When expression of either DKK 1 or PROK1 is knocked down on primary ESC, there is a decrease in expression of the markers of decidualization i.e. -IGFBP1, prolactin, and IL-11 in response to a decidualizing stimulus. Both DKK1 and PROK1 lie downstream of the progesterone $(\mathrm{P}) /$ cyclic AMP signaling cascade with potential for DKK1 to be regulated by $\mathrm{P}$ directly and indirectly via $\mathrm{P}$ mediated regulation of PROK1. It has been proposed that via a negative regulation of cellular proliferation and decidualization, PROK1 mediated DKK 1 expression contributes to the generation of a receptive endometrium and dysregulation of PROK1 mediated expression of DKK1 may be a contributing factor to infertility and recurrent pregnancy loss. Su et al. dem- 


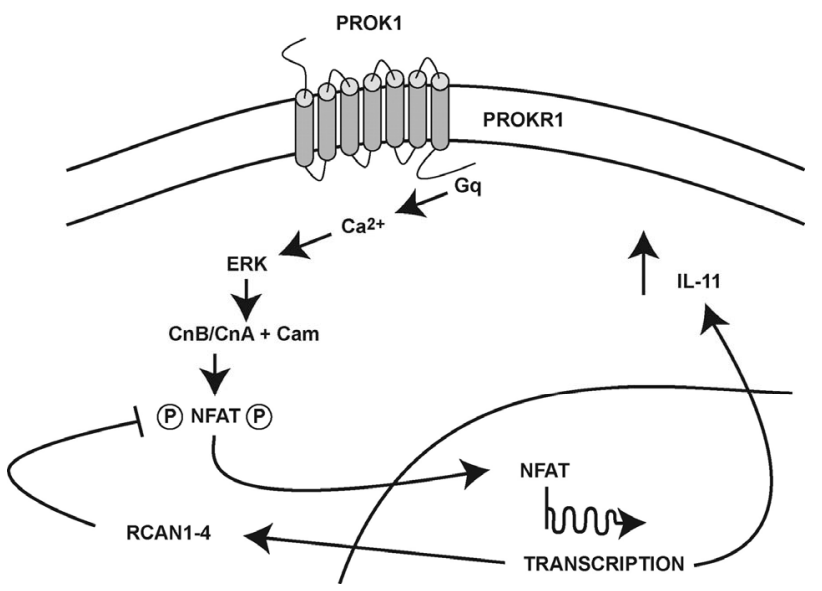

Figure 1. Schematic Representation of prokineticin 1 (PROK1) induction of regulator of calcineurin 1 isoform 4 (RCAN1-4)) and interleukin 11 (IL-11). Activation of PROKR1 by PROK1 results in the induction of IL-11 expression. This occurs via coupling to $\mathrm{Gq} / 11$ protein. This results in an intracellular increase in calcium which activates calcineurin and subsequently dephosphorylates cytoplasmic NFAT. This allows NFAT to migrate to the nucleus and bind to NFAT binding motifs in the promoter of IL-11 and induce its transcription. PROK 1 also upregulates RCAN1-4 expression which acts as a negative regulator and reduces the level of IL-11 transcription by binding to calcineurin and hence inhibiting NFAT dephosphorylation. $\mathrm{Gq}=\mathrm{Gq}$ protein alpha subunit, $\mathrm{Ca}^{+}=$intracellular ionized calcium ERK = extracellular signal regulated kinase, Cam-calmodulin, can $=$ Calcineurin catalytic subunit, $\mathrm{CnB}=$ Calcineurin regulatory subunit and NFAT $=$ nuclear factor of activated $\mathrm{T}$ cells. Courtesy ref no- 16 with permission.

onstrated a correlation between recurrent miscarriages and genetic polymorphisms in PROK1 and its receptors [40]. Aberrant elevation of PROK1 expression has also been associated with impaired decidualization and recurrent miscarriages [38]. EG-VEGF/PROK1 has been identified as one of the five new biomarkers of human endometrial receptivity in the natural cycle besides laminin- $\beta 3$, microfil associated protein 5 , angiopoietin like 1 , and nuclear localized factor 2 [41].

\subsection{Proks and the Feto Placental Unit}

During the first trimester of pregnancy PROK1 and PROKR1 are predominantly expressed in syncytiotrophoblasts with the highest expression found during crucial hypoxic period of placentation i.e. from 8 - 10 wks gestation in contrast to VEGF which is mostly localized to the cytotrophoblast and extravillous trophoblast cells. PROK1 is also expressed in specialized macrophages called hofbauer cells in the placental villi from 6 wks of gestation. PROKR1 mRNA expression was 80 times more as compared to PROKR2 mRNA in trophoblast [42] Both PROK and PROKR1 mRNA appear to be regulated by hypoxia, as supported by the presence of a hypoxic inducible factor (HIF- $\alpha$ ) binding sites in the promoter of both PROK1 and PROKR1 [3]. Supported bystudies in the mouse it has therefore been suggested that PROK1 may have a role in trophoblast differentiation and placental angiogenesis during early pregnancy, negatively regulate trophoblast invasion and that its circulating levels were significantly higher in preeclampsia patients $[43,44]$

\subsection{Prok in Third Trimester-Human Placenta-Inflammatory Mediator}

PROK is thought to have a role in immune regulation affecting differentiation of human bonemarrow cells onto distinct monocyte derived cell population primed for release of proinflammatory cytokines. Furthermore on stimulation with LPS, PROK1 primed monocyte. Macrophages expressed higher levels of TNF- $\alpha$ and IL-12 with a simultaneous decrease of anti-inflammatory IL-10, demonstrating that PROK, not only stimulates differentiation of monocytes, but also alters their functions by enhancing their proinflammatory potential [45]. Also in mouse tumour model and in isolated human immune cells it has been demonstrated that PROK2 and PROKR2 are upregulated in peripheral monocytes and neutrophils in response to G-CSF and GM-CSF [46,47]. Encouraged by their findings e.g. upregulation of IL-8 and COX-2 in a PROKR1 overexpressing human endometrial epithelial cell lines, Denison et al. postulated that PROK1 maybe a novel mediator of inflammatory response in term placenta and found PROK1 and PROKR1 expressed in term placenta, immunolocalizing to syncytiotrophoblast, cytotrophoblast, foetal endothelium and macrophages [48]. PROK1 induced a time dependent increase in expression of IL-8 and COX-2 which was dependent on Gq, phosphorylation of cSrc, epidermal growth factor receptor (EGFR) and MAPK kinase. PROK1 colocalized with IL-8 and COX-2 in placenta as revealed by double immunoflorescent immunohistochemistry. COX-2 derived prostaglandins alongside with chemokines such as IL-8 act to activate immune cells, enable vascular permeability and inflammatory cell infiltration during labour. Besides this prostaglandins are involved in cervical ripening and uterine contractions and thereby elevated COX-2 is an important marker of ongoing labour. Based on this and microarray analysis revealing expression of PROK2 increasing with the onset of labour in both the myometrium and cervix [49], it was proposed by Gorwiec et al. (2011) that PROK1 and PROKR1 may constitute an initiatory pathway for an inflammatory response in third trimester placenta [50]. PROK'S have also been shown to directly induce contractility of smooth muscles. Analysing the promoter regions of PROKS and PROKR'S highlights their potential regulation by pathways activated by infectious agents. Hence Catalano et al. (2010) further proposed that infection could result in premature 
activation of PROK expression and signaling in the uteroplacental unit and this would initiate a premature inflammatory and contractile cascade leading to preterm birth (Figures 2 and 3) [51]. Development of antagonism of PROK action might provide a suitable therapy for preterm labour in future that would target both inflammation and contractile pathways. Brouillet et al. (2010) showed PROK1 via PROKR1 mediated angiogenic affects, whereas PROK2 mediated cellular permeability [52]. They further showed hCG regulates PROK'S. It increases PROK1 from placental explants conditioned medium via transcriptional and post transcriptional effects. These hCG effects were mediated by cAMP via cAMP response elements present in the PROK1 promoter region suggesting hCG regulates PROK's and their receptors [53]. Chronic glucocorticoid (GC) exposure potentiates placental chorionic plate artery constriction, leading to aberrant fetoplacental vascular resistance in fetal growth restriction with PROK1 being one of vasoactive factors altered by chronic GC [54]. Blocking endogenous EG-VEGF might represent a valuable approach of impairing or inhibiting angiogenesis in steroidogenic derived embryonic tissues and could work as anti cancer strategy [55].

\subsection{Role of Prok in Fallopian Tube and Ectopic Pregnancy}

As highlighted by Jabbour et al. implantation is an inflammatory event and it is the proinflammatory signals which are required for establishment of a receptive endometrium [56]. Smoking and tubal damage from infection causes a proinflammatory phenotype in the fallopian tube which is believed to cause upregulation of proinflammatory cytokines which induce factors promoting endometrial receptivity, adhesion and invasion leading to ectopic pregnancy. PROK's are one of the family of proteins which cause upregulation of proinflammatory cytokines in the fallopian tube besides activin A, and interleukin 1 (IL-1). Shaw et al. (2010) found that the PROKR1 expression was increased in fallopian tubes (FT) from women who were smokers as compared to nonsmokers. They treated FT explants and immortalized oviductal epithelial cells (OE-E6/E7) with cotinine (an active metabolite of nicotine) at levels found in serum of smokers and found that in vitro PROKR1 expression were increased in tissue explants and OE-E6/E7 cells treated with cotinine in vitro which confirmed their in vivo findings [57]. Also they identified increased expression of nicotinic acetyl choline receptor alpha-7 (nAChR- $\alpha 7$ ) in the FT, and demonstrated cotinine signals through this receptor resulting in increased tubal PROKR1 expression [57]. In contrast they identified increased PROKR2 mRNA expression in FT's of women with serological evidence of past $C$. trachomatis infec- tion. In vitro treatment of same explants with C. trachomatis also resulted in increased PROKR2 expression very rapidly, confirming their in vivo findings. UV killed C. trachomatis also resulted in increased PROKR2 suggesting involvement of cell surface Pattern recognition

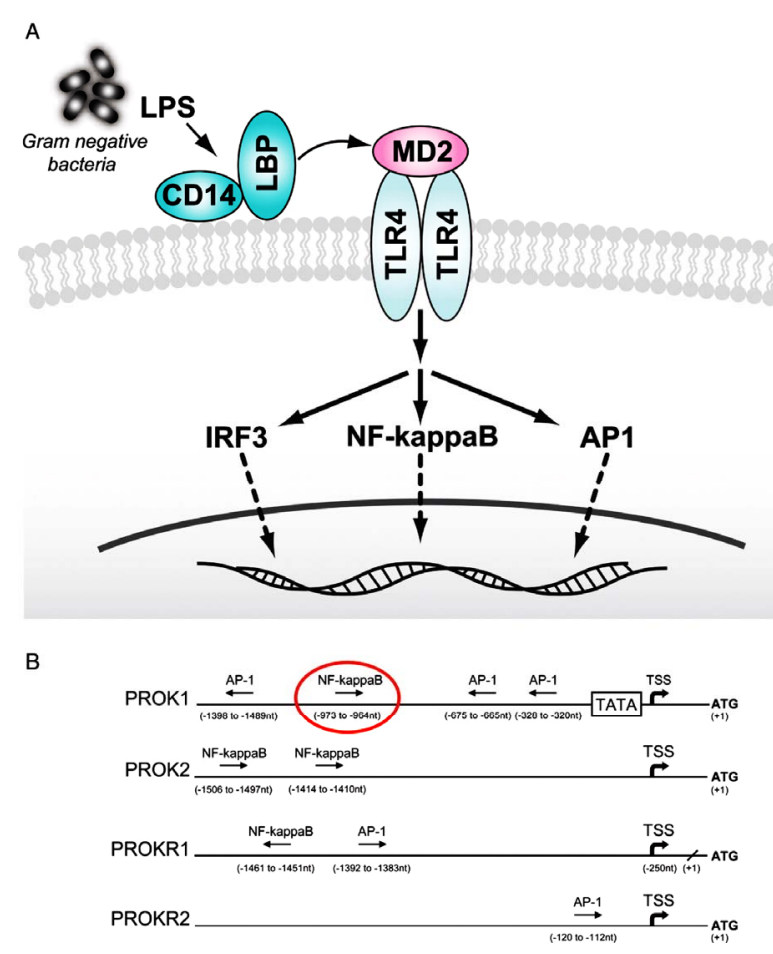

Figure 2. LPS signaling cascade and putative response elements in the promoters of the human prokineticins and their receptors. (A) LPS is the most potent antigenic component of the gram negative bacterial cell wall and is known to modulate the expression of various proinflammatory cytokines. LPS binds to the TLR 4 complex on the cell surface. TLR4 is thought to function as dimers and requires the co-receptor myeloid differentiation protein 2 (MD2) for full receptor sensitivity. CD14 and LPS binding protein (LBP) are known to facilitate the presentation of LPS. LPS-TLR4 binding leads to activation of transcription factors and complexes such as activator protein 1 (AP1), Interferon regulatory factor 3 (IRF3) and nuclear factor of kappa light polypeptide gene enhancer in $\mathrm{B}$ cells (NF-KappaB). Translocation of these factors to the nucleusleads to induction of genes that orchestrate the inflammatory response, such as interleukins IL-6, IL-8, prostaglandin endoperoxide synthase (PTGS2). (B) In silico analysis of the promoters of the human prokineticins and their receptors (PROK1, PROK2, PROKR1, and PROKR2) identified response elements in all gene promoters which could potentially respond to LPS stimulation. The promoter sequence for PROK1 possessed transcription factor binding elements with the highest matrix scores (reduced likelihood to represent a false positive transcription binding element) and was Also consereved in the mouse prok1 promoter. Response elements relative to start codon $(+1)$ for all promoters except PROKR1 where relative to end of first exon, start codon in second exon (/) TSS-transcriptional start site. Courtesy ref no-51-with permission. 


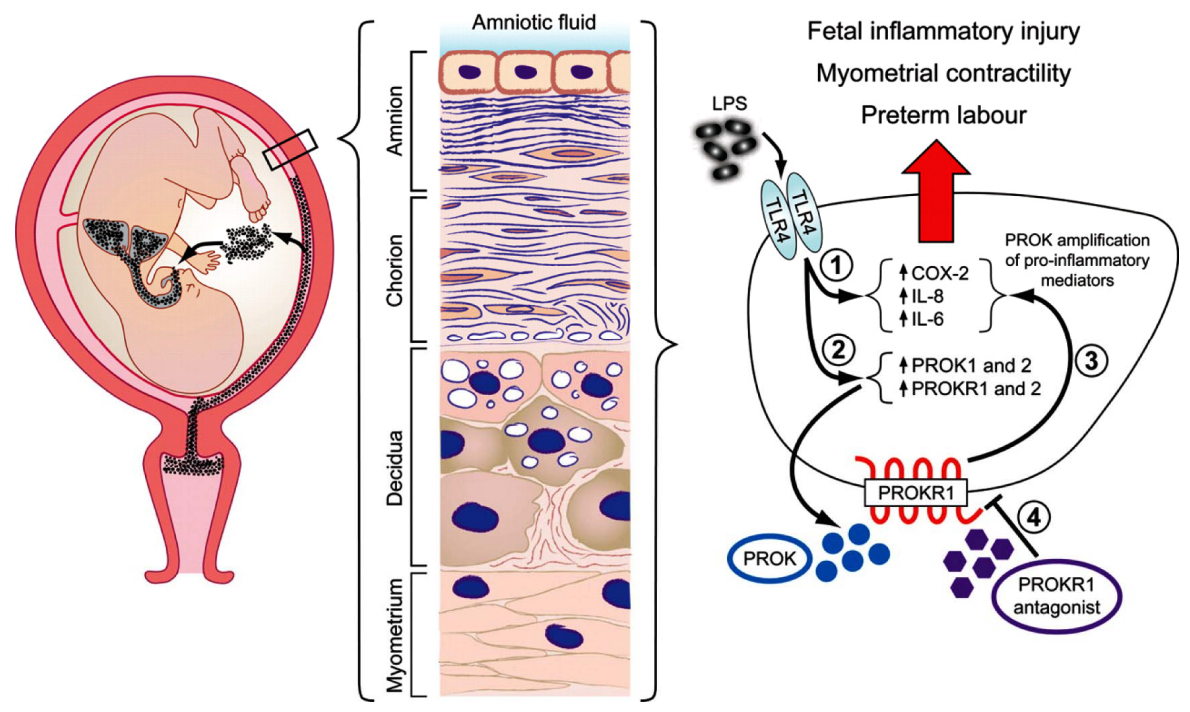

Figure 3. Proposed mechanism of action for PROK's and their receptors in preterm labour in response to bacterial infection. (A) Bacteria can be introduced to the pregnant reproductive tract and reach the amniotic cavity and fetus through different routes. As depicted, the most common route is via the cervix from the vagina which can result in inflammation of fetal membranes. Subsequent transmission across the membranes can result in infection of amniotic fluid and potentially the fetus. (B) TLR4 is expressed in various components of the uteroplacental unit, the cell depicted is stylized to represent any uterine cell. The bacterial component LPS can activate TLR4 resulting in the production of inflammatory mediators (COX-2, IL-8 and IL-6) key to the induction of myometrial contractility, preterm parturition and fetal injury 1) In addition, activation of TLR4, by LPS results in elevated expression of prokineticins and their receptors 2 ) which results in amplification of inflammatory mediators 3 ) inducing fetal inflammatory injury, myometrial contractility, and preterm laboir. The use of prokineticin receptor antagonists, 4) would inhibit PROK signaling and amplification of the proinflammatory mediators preventing myometrial contractility, preterm labour and fetal inflammatory injury. Courtesy ref no. 51-with permission.

receptor. Since activation of toll like receptor 2 (TLR2) in the FT epithelium by C. trachomatis had been demonstrated to lead to the dysregulation of factors involved in implantation and smooth muscle contractility, (like PROKR) and they identified activation of TLR2 in the tubal epithelium with subsequent activation of NF-KB in response to $C$. trachomatis expression which suggests TLR2 activation and induction of inflammatory phenotype would be an early feature of ectopic pregnancy. Elevated PROKR2 expression in women with past $C$. trachomatis infection without acute infection suggests that TLR2 may also be responsible for longacting immuneresponses generated by C. trachomatis in FT's [58]. Since PROK's upregulate LIF and increased LIF expression in FT at implantation site compared to adjacent sites has been demonstrated in chronically inflammed tubes [59], they proposed that PROKR expression in response to C. trachomatis expression and cigarette smoke may lead to an increased PROK signaling resulting in upregulation of factors like LIF which signal to embryo regarding the suitably of environment for implantation [58].

\section{PROK'S IN MALE REPRODUCTIVE FUNCTION}

PROK1 is expressed from 14 weeks of pregnancy until term in human fetal testis. In adult testis PROK1 is strongly expressed in leydig cells (testosterone (Tn) producing) only in contrast to VEGF which is expressed in both leydig and sertoli cells. PROK2 is restricted largely to primary spematocytes $[60,61]$. Both PROKR's are expressed within testis to vascular endothelial cells. In human testis PROKR1 is expressed at higher levels as compared to PROKR2, whereas they are expressed equally in mouse testis [60]. The 14-wk point is crucial time for human testis development as with PROK1 expression, the fetal production of another protein, steroidogenic acute regulatory protein (StAR) involved in Tn production begins. Onset of PROK1 mediated angiogenesis at this time may be critical for normal endocrine function. Angiogenesis-dependent PROK1 secretion may permit efficient transport of newly secreted $\mathrm{Tn}$ to other target tissues and may allow the transport of steroidogenic substances and regulatory hormones e.g. gonadotropins 
from periphery towards testis [62]. Lin et al. 2002 proposed that like PROK1, PROK2 functions as a mitogen, chemoattractant, survival factor in adrenal cortical capillary epithelial cells (ACE) [63]. Thus PROK's function as regulators of proliferation and formation of fenestrae in human testis vasculature [60]. In a pilot genome wide association study, atagged single nucleotide polymorphism in close proximity to PROK2 gene has been shown to be associated with oligozoospermia/azoospermia in men [64]. Collectively these observations suggest a role of PROK1 pathway in regulating testicular function and spermatogenesis. Besides that Samsung et al. 2004 found PROK1 expressed in leydig cell tumours but not in seminomas whereas VEGF a powerful angiogenic factor was strongly expressed in seminoma but very weakly in leydig cell tumours [62]. PROK2 expression has been found to be increased by varicocoele induction in rat testis and it may have a role in varicocoele induced infertility [65].

PROK's expression have been reported in prostate along with their receptors $[1,16,66]$. But at the protein level PROK1 expression has been reported only in hyperplastic and cancerous tissue, localized in glandular epithelial cells and progressively increased with the prostate cancer [65]. The role innormal prostate is uncertain as yet.

\section{ROLE OFPROK2 PATHWAY IN REPRODUCTION}

PROK2 is localized in hypothalamic regions critical for GnRH action e.g., preoptic area, arcuate nucleus, and median eminence. It is also expressed in nucleus accumbens, premammilary nucleus, islands of calleja and amygdala-regions associated with reproductive and feeding behavior. It is also present in suprachiasmatic nucleus and PROK2 expressing neurons extend their connections to the preoptic area where GnRH neurons reside. There is ample evidence that circadian signals contribute directly to neuroendocrine control of reproduction $[67,68]$.

\subsection{GnRH Deficiency in PROK2 and PROKR Knockout Mice}

The role of PROK pathway was accidentally discovered in the murine knock out of prok2 and prokr2 while studying the role in gastrointestinal motility and a disruption of neurogenesis of their olfactory bulbs accompanied by a dramatic reduction in GnRH expressing cells in the median POA along with absence of GnRH neuronal projections in the median eminence [69] was found. These findings were a phenocopy of the anatomical observations seen in Kallmanns syndrome (KS) in humans although till then nomurine model to study KS was available as KAL1 gene had never been located in the mouse genome. Approximately $50 \%$ of prok 2 knockout mice show asymmetrical development of olfactory bulb. The GnRH neurons that do manage to reach hypothalamus are insufficient in numbers/function to initiate reproductive axis competency. This implies that PROK2 may impact on GnRH neuronal integrity through additional mechanisms besides olfactory bulb neurogenesis [7,69]. Since PROKR2 is not expressed in GnRH neurons, elucidation of molecular mechanisms by which PROK2 system regulates GnRH neuronal development and function remains a big challenge. The arrested GnRH neurons formed a fibrocellular mass just beyond cribriform plate immediately prior to their entry into the forebrain [70]. Although all prokr2 mice showed a dramatic decrease in the olfactory bulb (OB) size [70] only half exhibit an asymmetric olfactory bulb development [69], suggesting a potential redundancy between the two ligands PROK1 and PROK2 in the neurogenesis of OB. prok2 and prokr2 knockout mice with reduced $\mathrm{GnRH}$ neurons have a low GnRH secretion resulting in low gonadotropins and impairment of sexual maturation in both male and female mice. Male prok2 and prokr2 knockouts show small seminiferous tubules which lack lumens, absent haploid spermatocytes and spermatids [69]. Under normal conditions prok 2 is heavily expressed in diploid spermatocytes after meiotic division, suggesting a possible role of prok2 in final stages of spermatogenesis. Although in female mice incomplete follicular development occurs in mice and humans ovarian function gets restored with gonadotropin replacement.

\subsection{Genetic Causes of Isolated GnRH Deficiency and PROK2}

To date roughly $32 \%$ of a large cohort of GnRH deficient patients $(\mathrm{n}=397)$ at the Massachussets general hospital have been linked to atleast one gene mutation knwn to cause human GnRH deficiency. These include a broad spectrum of phenotypes: 1) mild defect of GnRH secretion affecting only timing of puberty (delayed puberty), 2) an intermediary defect presenting as spontaneous puberty with subsequent development of permanent hypogonadism (acquired $\mathrm{HH}$ ) or a, 3) severe defect with complete/partial absence of puberty (reviewed in [71]). Early developmental genes such as KAL1, FGF8, FGFR1, NELF, CHD7, PROK2 and PROKR2 play a critical role in embryonic neuronal development and subjects with mutations in these genes present primarily with $\mathrm{KS}$. GnRH deficient patients also display a broadspectrum of nonreproductive phenotypes including facial midline defects, skeletal abnormalities and renal agenesis that can provide key clues to the underlying causal gene. 


\subsection{PROK2 and PROKR2 Mutations in Isolated GnRH Deficiency in Humans}

Following the murine models, Dode et al. (2006) screened 192 unrelated KS patients and found several DNA sequence changes in both PROK2 and PROKR2 without Any functional studies in the missense cases [72]. In contrast to murine knockout model majority of these rare sequence variants existed only in heterozygous state with four patients with heterozygous mutations in PROK2 and ten patients with heterozygous PROKR2 variants in patients with overt clinical phenotype. Only four patients showed a homozygous/compound heterozygous state, Following that Pittleloud et al. 2007 reported 3 siblings with GnRH deficiency (two brothers and one sister of Portuguese ethnicity and all of them harbouredloss of function homozygous deletion in the ligand, PROK2 which resulted in a biologically inactive 27 amino acid truncated protein [69]. Subsequently a large number of predominantly heterozygous loss of function mutations in both PROK2 and PROKR2 have now been reported in patients with both KS and nIHH by several groups. (Cole et al. (2008) [73], Leroy et al. (2008) [74], Sinisi et al. (2008) [75], Abreu et al. (2008) [76], Canto et al. (2009) [77], Sarfati et al. (2010) [78], Monnier et al. (2009)) [79]. Balasubriam et al. (2011) found a lot of puzzling observations after studying combined analysis of murine and human phenotypes [80].

1) Although neurodevelopmental role of PROK2 pathwayis key in GnRH development there is conspicuous absence of PROKR2 in both developing and mature GnRH neuron. This is further complicated by the recent findings of isolated congenital anosmia (ICA) without gonadotropin deficiency in 25 patients with ICA and olfactory bulb agenesis in whom detailed phenotype analysis and coding sequences of KAL1, FGR1, FGF8, PROK2 and PROKR2 were sequenced. Three PROKR2 mutations previously described in $\mathrm{KS}$, and one new PROK2 mutation were found and investigation of the families showed incomplete penetrance of these mutations, which confirms complexity of GnRH neuron development in humans [81]. This challenges the proposition by Balasubramaniam et al. (2011) that an hitherto unknown early neonatal population expressing PROKR2 may govern the migration of the GnRH neuron by virtue of their chemoattractive interaction with the developing OB which shows a high level of PROK2 expression [80].

2) As compared to mice which develop a pure neurodevelopmental phenotype i.e. a combination of olfactory and reproductive phenotype, humans with PROK2/PROKR2 mutations present with both KS as well as normosmic IHH. This observation suggests that PROK2 pathway plays a key role in both neurodevelopmental and neuroendocrinefacets of GnRH ontogeny. However stu- dying the olfactory phenotypic spectrum in IHH patients Lewkowitz-Shpuntoff et al. 2012 found $31.5 \%$ patients were anosmic, $33.6 \%$ hyposmic and $34.9 \%$ normosmic out of 286 cases of IHH studied [82]. Although traditionally it is believed that $\mathrm{KS}$ and $\mathrm{nIHH}$ were distinct clinical entities with KS representing a neurodevelopmental phenotype with a primary defect in GnRH neuronal migration, whereas $\mathrm{nIHH}$ subjects represent a pure neuroendocrine defect in GnRH secretion/action. Most genes identified in subjects with KS have been shown to play a predominant GnRH migratory role (KAL1, NELF/ PROK2/PROKR2/FGF8/FGFR1) [83], whereas genes identified in nIHH subjects have been shown to primarily affect neuroendocrine regulation of $\mathrm{GnRH}(\mathrm{GnRH} 1$, GnRHR, TAC3, TACR3, KISS1R) [84]. Thus $1 / 3$ patients of IHH displaying a hyposmic phenotype of which $39.5 \%$ harbored mutations in genes affecting neuronal migration like KAL1/PROK2/FGF signalling, suggest a pathophysiological overlap between KS and $\mathrm{nIHH}$, while all PROKR2 variants were monoallelic and associated with anosmia/normosmia.

3) While in mice heterozygous gene deletions are reportedly normal, in humans mostly clinical syndromes are found with the heterozygous state. The proposed hypothesis are a) an autosomal dominant mode of inheritance/haploinsufficiency state; b) a dominant negative effect of mutations; or c) oligogenic interactions with other genes/nongenic factors. Although an autosomal dominant state has not been supported [79], oligogenic interactions with mutations in other genes known to cause GnRH deficiency have been documented in some patients with heterozygous mutations in PROK2/PROKR2 $[73,77,78]$. However a dominant negative role for the mutations is still possible, requiring allelic dosing experiments in robust cellular model/organ system to confirm or refute the hypothesis. 4) Humans having identical PROK2/PROKR2 mutations show considerable variations in the expression and penetrance of both their olfactory and reproductive phenotypes. 5) The in vitro functional studies of human PROKR2 mutations show discordant effects on the various intracellular signaling pathways suggesting unique structure functional relationship of the PROKR2 missense variants that have been systematically assessed, some mutations show significant impairment of receptor function (L173R, P290S, W178 S), while others (R85C, R248Q, V331M), preferentially affect either the intracellular calcium influx or the MAPK signaling cascade (R357W) [73,79]. The intracellular signaling effect of missense variants show diverse features. The discordant effects of PROKR2 mutations may indicate domain specific effects, with more detailed characterization will allow mapping of structure activity relationships and identify critical structural elements of the PROKR2 receptors. Peng et al. (2011) identi- 
fied PROK2 dose dependently increased the cytoplasmic calcium in cells transfected with WT PROKR2 however R164 Q mutant (mutation in 2nd intracellular (IL2) loop) PROKR2 showed normal cell surface expression and ligand binding capacity, but lost the PROKR2 signalling. R164 Q mutation disrupted the interaction of IL2 loop to the Gaq, Gai, And Gai6 proteins [85]. A positivecharged aminoacid at this position is required for proper function, and the signaling efficacy and potency depends on the net amount of positive charges. They also showed that the interactive partner of Arg-164 may localize in the $\mathrm{C}$ terminal five residues of $\mathrm{G} \alpha \mathrm{q}$ protein. A series of mutation analysis indicated that the basic amino acids at the C terminus of IL2 loop may function cooperatively in GPCR's. Studying the variants of first intracellular loop (ICL 1) of PROKR2 (R80C, R85C and R85H) identified in patients with $\mathrm{HH}$, Abreu et al. (2012) found that the R85C and R85H PROKR2 mutations, modestly interfered with receptor function, in contrast to $\mathrm{R} 80 \mathrm{C}$ PROKR2 mutations which lead to marked reduction in receptor activity. Cotransfection of wild type and R80C mutant could exert a dominant negative effect on WT PROKR2 in vitro by interfering with WT receptor expression, hence identifying importance of Arg 80 in ICL1 for PROKR2 expression and demonstration that R80C PROKR2 exerts a dominant effect on WT PROKR2 [86].

6) Apotential dual effect of PROK2 mutations, as few male patients with mutations of PROK2 pathway display spermatogenic abnormalities, despite gonadotrop in treatment as shown by Sinisi et al. [75] oligozoospermia persisted suggesting a primary gonadal defect as well. As outlined in role in testicular function, these observations suggest a role of PROK2 pathway in regulating primary testicular function and spermatogenesis. While in contrast to men, in women and female mice with PROK2 deficiency ovarian function gets restored with gonadotropin replacement.

7) GnRH deficient patients with PROK2/PROKR2 mutations have been shown to be associated with nonreproductive feautures eg bikinesis and hearing loss has been seen in a minority of patients of PROK2/PROKR2 mutation, no cleft lip/renal agenesis has been associated with PROK2 mutations [87]. Also no disturbances in circadian rhythm/sleep disorders identified although in a case controlled Japanese study in patients with mood disorders (151 bipolar patients, 319 with major depressive disorders and 319 controls), Kishi et al. (2009) found a tagging SNP in PROKR2, associated with major depressive disorder [88]. Although in prok and prokr knockout mice increased neonatal mortality is reported it has only been reported in 1 family by Pitteloud 2007 with PROK2 mutations, but not in other families or pedigrees with PROK2 mutation [69].

\subsection{PROKR2 in Hypothalamic Amenorrhea}

Although functional hypothalamic amenorrhea is considered a reversible form of GnRH deficiency, triggered by stressors like excessive exercise, nutritional defects, or psychological distress Caronia et al. (2011) analyzing 55 patients of HA found 6 heterozygous mutations in 7 of 55 patients, of which two were in the PROKR2 gene ( $\mathrm{R} 85 \mathrm{H}$ and $\mathrm{L} 173 \mathrm{R}$ ), both of which were loss of function mutations, besides FGR1, GNRHR and KAL1 gene mutations suggesting that there is a genetic predisposition to HA in view of differing susceptibility in women to develop HA in response to stress [89].

\subsection{Role of PROK2 Pathway in Pituitary Development}

With the proposed role of PROK2 Pathway in angiogenesis and neuronal migration, Reynaud et al. 2012 reported two heterozygous PROKR2 mutations ( $p$. Leu 173 Arg and pArg 85 His) which had been previously reported in isolated hypogonadotropic hypogonadism (IHH) and a novel PROKR2 variant (pAla 51 Thr) which in contrast to other mutations did not impair receptor signaling. While studying 72 index cases of hypopituitarism with pituitary stalk interruption syndrome and thus proposed a potential role of PROK pathway in pituitary development and hypothesized that ectopic posterior pituitary may be a consequence of defective axonal projections along the pituitary stalk or defective angiogenesis of hypophyseal portal circulation [90]. Similarly McCabe et al. 2013 detected five PROKR2 variants in patients of congenital hypopotuitarism $(\mathrm{CH})$, including septooptic dysplasia (SOD). Of 422 patients of complex forms of $\mathrm{CH}$, they detected 5 PROKR2 variants in 11 patients with SOD/CH, novel p.G371R, and previously reported p.A51T, p.R851, p.L173R, and p.R268C-the latter 3 being known to be functionally deleterious variants [91]. Downregulation of PROK1 in pituitary adenomas except LH secreting adenomas suggests LH might be involved in PROK1 secretion [92].

\section{OTHER POTENTIAL ACTIONS}

In view of various physiological functions, it was proposed by Levit et al. (2011) to identify binding sites of known antagonists and additional potential binders to facilitate studying the novel PROKR's with the view that blocking PROKR's may serve as therapeutic tool for various diseases, including acute pain, inflammation and cancer. Potential human PROKR ligands with novel scaffolds identified by ligand based pharmacophore models derived from known antagonists and virtual 
screening performed on Drugbank dataset identified several HIV protease inhibitors for which endothelial cell dysfunction is a documented sideeffect. Their results suggest that the side effects might be due to inhibition of the PROKR signaling pathway. Docking of known binders to a 3D homology model of PROKR1 is in agreement with the well established canonical TM-bundle binding site of family A GPCR'S. With the exception of a single loop residue that might be perused in the future for obtaining subtype-specific regulation, their results suggest an identical TM-bundle binding site for PROKR1 and PROKR2, and variable regions may provide subtype specificity [93].

\section{CONCLUSIONS-THERAPEUTIC IMPLICATIONS AND FUTURE DIRECTIONS}

PROK1 has been found to be involved in the process of embryo implantation and initiation of parturition. It has a role in the pathogenesis of tubal pregnancy secondary to smoking, testicular leydig cell tumors, and other cancers. As PROK1 leads to the expression of various genes stimulated in endometrium and uNK cells including LIF, COX-2, IL-8 and IL-11, this helps in understanding the improved implantation despite knocking off VEGFR2 by cabergoline [94] in the prevention of OHSS attributable to role of PROK1 in early angiogenesis. This knowledge can be used to improve implantation and success rates in IVF and ART. Inhibiting PROK action may delay the onset of preterm labour by suppressing myometrial contractility and reducing the premature onset of inflammatory pathways known to be critical for induction of labour. Simultaneously this PROK signaling suppression may also prove beneficial to preterm neonatal outcome by reducing inflammation associated injury to the fetal brain and lungs. Astrategy for prevention of tubal pregnancies in smokers can be achieved by understanding aetiopathogenesis of increased LIF expression in tubal mucosa and anticancer strategies in male and female cancers can be evolved.

PROK2 signaling is a critical regulator of olfactory bulb morphogenesis and sexual maturation in mammals. Although PROK2 and PROKR2 have emerged as critical regulators of reproduction with PROK2 and PROKR2 mutations having a role in KS, the exact mode of inheritance however remains controversial. The complex biology of GnRH neuronal development and function has not been fully understood. The recent discovery of mutations in the PROK2 pathway in human GnRH deficiency has provided some help, yet many challenges and questions have been opened up. For e.g., in both murine and human PROK2/PROKR2 mutations in homozygous state have provided compelling evidence for the critical role played by the PROK pathway in embryonic migration of
GnRH neurons. But the presence of PROK2/PROKR2 mutations in nIHH subjects and the reproductive abnormalities found in prok knockout mice with partial olfactory bulb development is suggestive a potential role for PROK2 beyond GnRH neuronal migration. Further GnRH neurons don't express PROK receptors which make the matter further perplexing. Also, although mice with heterozygous mutations do not show overt defects, humans with missense mutations present with clinical phenotypes. Although a monogenic recessive mode of inheritance has been clearly demonstrated, it has been done in very few cases. On top of that many of the heterozygous mutations have also been identified in clinically unaffected individuals. Moreover a dominant negative effect of the heterozygous mutations of PROKR2 was not demonstrated by in vitro studies, which argues against a monogenic dominant transmission. Hence potential digenic and oligogenic transmission has been suggested. Many of the heterozygous mutations of PROKR2 have also been identified in clinically unaffected individuals, which raises the question of actual contribution of PROK'S to the HH phenotype. Potential digenic and oligogenic transmission [95] is suggestive; but still further studies are necessary to confirm the actual pathogenic role of heterozygous PROKR2 mutations with GnRH neurons not expressing PROK receptors suggests an intermediary pathway may mediate PROK2 system and the GnRH neuronal network which needs to be elucidated. The mechanism of PROK signaling is also ill understood with the interacting proteins, chaperones, transcription factors or if any 2nd messenger systems exist need to be unearthed.

\section{REFERENCES}

[1] Li, M., Bullock, C.M., Knauer, D.J., Ehlert, F.J. and Zhou, Q.Y. (2001) Identification of two prokineticin cDNAs: Recombinant proteins potently contract gastrointestinal smith muscle. Molecular Pharmacology, 59, 692-698.

[2] Mollay, C., Wechselberger, C., Mignogna, G., Neegri, L., Melchiorri, P., Barra, D. and Kreil, G. (1999) Bv8, a small protein from frog skin and its homologue from snake venom induce hyperalgesia in rats. European Journal of Pharmacology, 374, 189-196.

doi:10.1016/S0014-2999(99)00229-0

[3] LeCouter, J., Kowalski, J., Foster, J., Hass, P., Zhang, Z., Dillard-Telm, L., Frantz, G., Rangell, L., Deguzman, L., Keller, G.A., Peale, F., Gurney, A., Hillan, K.J. and Ferrara, N. (2001) Identification of an angiogenic mitogen selective for endothelial gland endothelium. Nature, 412, 877-884. doi:10.1038/35091000

[4] LeeCouter, J.J., Lin, R., Frantz, G., Zhang, Z., Hillan, K. and Ferrara, N. (2003) Mouse endocrine gland-derived vascular endothelial growth factor: A distinct expression pattern from its human ortholog suggests different roles as a regulator of organ specific angiogenesis. Endocri- 
nology, 144, 2606-2616. doi:10.1210/en.2002-0146

[5] Chen, J., Kuie, C., Sutton, S., Wilson, S., Yu, J.X., Kamme, F., Mazur, C., Lovenberg, T. and Liu, C. (2005) Identification and pharmacological characterization of prokineticin $2 \beta$ as a selective ligand for prokineticin receptor 1. Molecular Pharmacology, 67, 2070-2076.

doi:10.1124/mol.105.011619

[6] Urayama, K., Guilini, C., Messaddeq, N., Hu, K., Stteenman, M., Kuurose, H., Ert, G. and Nebigil, C.G. (2007) The prokinecitin receptor-1 (GPR73) promotes cardiomyocyte survival and angiogenesis. The FASEB Journal, 21, 2980-2993. doi:10.1096/fj.07-8116com

[7] Ng, K.L., Li, J.D., Cheng, M.Y., Leslie, F.M., Lee, A.G. and Zhou, Q.Y. (2005) Dependence of olfactory bulb neurogenesis on prokinecitin 2 signalling. Science, 308, 1923-1927. doi:10.1126/science. 1112103

[8] Negri, L., Lattanzi, R., Giannini, E., Canestrelli, M., Nicotra, A. and Melchoorri, P. (2009) Chapter 11 Bv8/ prokineticins and their receptors: A new pronociceptive system. International Review of Neurobiology, 85, 145157. doi:10.1016/S0074-7742(09)85011-3

[9] Monnier, J. and Samson, M. (2008) Cytokine properties of prokineticins. The FEBS Journal, 275, 4014-4021. doi:10.1111/j.1742-4658.2008.06559.x

[10] Maldonando-Perez, D., Evans, J., Denison, F., Millar, R.P. and Jabbour, H.N. (2007) Potential roles of the prokineticins in reproduction. Trends in Endocrinology \& Metabolism, 18, 66-72. doi:10.1016/j.tem.2006.12.002

[11] Soga, T., Matsumoto, S., Oda, T., Saito, T., Hiyama, H., Takasaki, J., Kamohara, M., Ohishi, T., Matsushime, H. and Furuichi, K. (2002) Molecular cloning and characterization of prokineticin receptors. Biochemica et Biophysica Acta, 1579, 173-179.

[12] Kaser, A., Winklmayr, M., Lepperdinger, G. and Kreil, G. (2003) The AVIT family. Secreted cysteine rich vertebrate proteins with diverse functions. EMBO Reports, 4, 469-473. doi:10.1038/sj.embor.embor830

[13] Zhang, L., Yang, N., Conejo-Garcia, J.R., Katsaros, D., Mohamed-Hadley, A., Fracchioli, S., Schlienger, K., Toll, A., Levine, B., Rubin, S.C. and Coukos, G. (2003) Expression of endocrine gland-vascular endothelial growth factor in ovarian carcinoma. Clinical Cancer Research, 9, 264-272.

[14] Ferrara, N., Frantz, G., LeCouter, J., Dillard-Telm, L., Pham, T., Dreaksharapu, A., Giordano, T. and Peale, F. (2003) Differential expression of the angiogenic factor genes vascular endothelial growth factor (VEGF) and endocrine gland-derived VEGF in normal and polycystic human ovaries. The American Journal of Pathology, 162, 1881-1893. doi:10.1016/S0002-9440(10)64322-2

[15] Fraser, H.M., Bell, J., Wilson, H., Taylor, P.D., Morgan, K., Anderson, R.A. and Duncan, W.C. (2005) Localization and quantification of cyclic changes in the expression of endocrine gland vascular endothelial growth factor in the human corpus luteum. The Journal of Clinical Endocrinology \& Metabolism, 90, 427-434.

[16] Lin, D.C., Bullock, C.M., Ehlert, F.J., Chen, J.L., Tian, H. and Zhou, Q.Y. (2002) Identification and molecular characterization of two closely related $\mathrm{G}$ protein-coupled receptors activated by prokineticins/endocrine gland vascular endothelial growth factor. The Journal of Biological Chemistry, 277, 19276-19280. doi:10.1074/jbc.M202139200

[17] Kisloiuk, T., Podlovni, H., Spanel-Borowski, K., Ovadia, O., Zhou, Q.Y. and Meidan, R. (2005) Prokineticins (endocrine gland-derived vascular endothelial growth factor and Bv8) in the bovine ovary: Expression and role as mitogens and survival factors for corpus luteum-derived endothelial cells. Endocrinology, 146, 3950-3958. doi:10.1210/en.2005-0297

[18] Kisliouk, T., Podlovni, H. and Meidan, R. (2005) Unique expression and regulatory mechanisms of EG-VEGF/ prokineticin 1 and its receptors in the corpus luteum. Annals of Anatomy, 187, 529-537. doi:10.1016/j.aanat.2005.07.005

[19] Kisliouk, T., Friedman, A., Klipper, E., Zhou, Q.Y., Schams, D., Alfraidy, N. and Meidan, R. (2007) Expression pattern of prokineticin 1 and its receptors in bovine ovaries during the estrous cycle: Involvememt in corpus luteum regression and follicular atresia. Biology of Reproduction, 76, 749-758. doi:10.1095/biolreprod.106.054734

[20] Plaks, V., Kachenko, V., Dekel, N. and Neeman, M. (2006) MRI analysis of angiogenesis during mouse embryo implantation. Magnetic Resonance in Medicine, 55, 1013-1022.

[21] Plaks, V., Bimberg, T., Beerkutzki, T., Sela, S., Ben Yashar, A., Kalchenko, V., Mor, G., Keshet, D., Dekel, N., Neeman, M. and Jung, S. (2008) Uterine DC's are crucial for decidua formation during embryo implantation. Journal of Clinical Investigation, 118, 3954-3965.

[22] Battersby, S., Critchley, H.O., Morgan, K., Millar, R.P. and Jabbour, H.N. (2004) Expression and regulation of the prokineticins (endocrine gland derived vascular endothelial growth factor and Bv8) and their recptors in the human endometrium across the menstrual cycle. The Journal of Clinical Endocrinology \& Metabolism, 89, 2463-2469. doi:10.1210/jc.2003-032012

[23] Evans, J., Catalano, R.D., Morgan, K., Critchley, H.O., Millar, R.P. and Jabbour, H.N. (2008) Prokineticin 1 signalling and gene regulation in early human pregnancy. Endocrinology, 149, 2877-2887. doi:10.1210/en.2007-1633

[24] Evans, J., Catalano, R.D., Brown, P., Sherwin, R., Critchley, H.O., Fazleabas, A.T. and Jabbour, H.N. (2009) Prokineticin 1 mediates fetal-maternal dialogue regarding endometrial leukemia inhibitory factor. The FASEB Journal, 23, 2165-2175. doi:10.1096/fj.08-124495

[25] Maldonado-Perez, D., Evans, J., Denison, F., Millar, R.P., Thompson, E.A. and Jabbour, H.N. (2009) Prokineticin 1 modulates IL-8 expression via the calcineurin/NFAT signaling pathway. Biochimica et Biophysica Acta, 1793, 1315-1324. doi:10.1016/j.bbamcr.2009.03.008

[26] Ngan, E.S., Lee, K.Y., Yeung, W.S., Ngan, H.Y., Ng, E.H. and Ho, P.C. (2006) Endocrine gland-derived vascular endothelial growth factor is expressed in human periimplantation endometrium, bit not in endometrial carcinoma. Endocrinology, 147, 88-95. 
doi:10.1210/en.2005-0543

[27] Cook, I.H., Evans, J., Maldonaldo-Perez, D., Critchley, H.O., Sales, K.J. and Jabbour, H.N. (2010) Prokineticin 1 (PROK1) modulates interleukin (IL)-11 expression via prokineticin receptor 1 (PROKR1) and the calcineurin/ NFAT signaling pathway. Basic Science of Reproductive Medicine, 16, 158-169. doi:10.1093/molehr/gap084

[28] Dimitriadis, S., Robb, L. and Salamonsen, L.A. (2002) Interleukin 11 advances progesterone induced decidualization of human endometrial stromal cells. Basic Science of Reproductive Medicine, 8, 636-643. doi:10.1093/molehr/8.7.636

[29] Dimitriadis, E., Stoikos, C., Baca, M., Fairlie, W.D., McCoubrie, J.E. and Salamonsen, L.A. (2005) Relaxin and prostaglandin E2 regulate interleukin 11 during human endometrial stromal cell decidualization. The Journal of Clinical Endocrinology \& Metabolism, 90, 34583465. doi:10.1210/jc.2004-1014

[30] Roh, C.R., Budhraja, V., Kim, H.S., Nelson, D.M. and Sadosky, Y. (2005) Microarrey based identification of differentially expressed genes in hypoxic term human trophoblasts and in placental villi of pregnancies with growth restricted fetuses. Placenta, 26, 319-328. doi:10.1016/j.placenta.2004.06.013

[31] Rimon, E., Chen, B., Shanks, A.L., Nelson, D.M. and Sadovsky, Y. (2008) Hypoxia in human trophoblasts stimulates the expression and secretion of connective tissue growth factor. Endocrinology, 149, 2852-2958. doi:10.1210/en.2007-1099

[32] Oh, S.Y., Song, S.E., Seo, E.S., Kim, K.H., Choi, S.J., Suh, Y.L., Sadovsky, Y. and Roh, C.R. (2009) The expression of connective tissue growth factor in pregnancies complicated by severe preeclampsia or fetal growth restriction. Placanta, 30, 981-987. doi:10.1016/i.placenta.2009.08.006

[33] Waddell, J.M., Evans, J., Jabbour, H.N. and Denison, F.C. (2011) CTGF expression is upregulated by PROK1 in early pregnancy and influence ahtr-8/Syneo Cell adhesion and network formation. Human Reproduction, 26, 67-75.

[34] Macdonald, L.J., Sales, K.J., Grant, V., Brown, P., Jabboir, H.N. and Catalano, R.D. (2011) Prokineticin 1 induces Diccopf1 expression and regulates cell proliferation and decidualization in the human endometrium. $\mathrm{Ba}$ sic Science of Reproductive Medicine, 17, 626-636. doi:10.1093/molehr/gar031

[35] Wallace, A.E., Catalano, R.D., Anderson, R.A. and Jabbour, H.N. (2011) Chemokine (C-C) motif ligand 20 os regulated by PGF (2alpha)-F-prostanoid receptor signaling in endometrial adenocarcinoma and promote cell proliferation. Molecular and Cellular Endocrinology, 331, 129-135. doi:10.1016/j.mce.2010.08.018

[36] Tulac, S., Overgaard, M.T., Hamilton, A.E., Jumbe, N.L., Suchanek, E. and Giudice, L.C. (2006) Diccopf-1 an inhibitor of Wnt signaling, is regulated by progesterone in human endometrial stromal cells. The Journal of Clinical Endocrinology \& Metabolism, 91, 1453-1461. doi:10.1210/jc.2005-0769

[37] Kane, N., Jones, M., Brosens, J.J., Saunders, P.T., Kelly, R.W. and Critchley, H.O. (2008) Transforming growth factor-beral attenuates expression of both the progesterone receptor and dickkopf in differentiated human endometrial stromal cells. Molecular Endocrinology, 22, 716728. doi:10.1210/me.2007-0316

[38] Salker, M., Teklenburg, G., Molokhia, M., Lavery, S., Trew, G., Aojanepang, T., Mardon, H.J., Lokugamage, A.U., Rai, R., et al. (2010) Natural selection of human embryos: Impaired decidualization of endometrium disables embryo-maternal interaction and causes recurrent pregnancy loss. PLoS One, 5, e10287. doi:10.1371/journal.pone.0010287

[39] Tiberi, F., Tropea, A., Romani, F., Apa, R., Marana, R. and Lanzone, A. (2010) Prokineticin 1, homeobox A10 and progesterone receptor messenger ribonucleic acid expression in primary cultures of endometrial stromal cells isolated from endometrium of healthy women and from eutopic endometrium of women with endometriosis. Fertility and Sterility, 94, 2558-2563. doi:10.1016/j.fertnstert.2010.03.006

[40] Su, M.T., Lin, S.H., Lee, I.W., Chen, Y.C., Hsu, C.C., Pan, H.A. and Kuo, P.L. (2010) Polymorphisms of endocrine gland-derived vascular endothelial growth factor geneand its receptor genes are associated with recurrent pregnancy loss. Human Reproduction, 25, 2923-2930. doi:10.1093/humrep/deq256

[41] Haouzi, D., Mahmoud, K., Fourar, M., Bendhaou, K., Dechaud, H., Vos, J.D., Rerne, T., Dewailly, D. and Hamamah, S. (2009) Identification of new biomarkers of human endometrial receptivity in the natural cycle. $\mathrm{Hu}$ man Reproduction, 24,198-205. doi:10.1093/humrep/den360

[42] Hoffmann, P., Feige, J.J. and Alfaidy, N. (2006) Expression and oxygen regulation of endocrine gland derived vascular endothelial growth factor/prokineticin-1 and its recptors in human placenta during early pregnancy. Endocrinology, 147, 1675-1684. doi:10.1210/en.2005-0912

[43] Hoffmann, P., Feige, J.J. and Alfaidy, N. (2007) Placental expression of EG-VEGF and its receptors PKR1 (prokineticin receptor-1) and PKR2 throughout mouse gestation. Placenta, 28, 1049-1058. doi:10.1016/j.placenta.2007.03.008

[44] Hoffmann, P., Saoudi, Y., Benharouga, M., Graham, C.H., Schaal, J.P., Mazouni, C., Feige, J.J. and Alfaidy, N. (2009) Role of EG-VEGF in human placentation: Physiological and pathological implications. Journal of Cellular and Molecular Medicine, 13, 2224-2235. doi:10.1111/j.1582-4934.2008.00554.x

[45] Dorsch, M., Qiu, Y., Soler, D., Frank, N., Duong, T., Gooearl, A., O’Neil, S., Lora, J. and Fraser, C.C. (2005) PK1/EG-VEGF-induces monocyte differentiation and activation. Journal of Leukocyte Biology, 78, 426-434. doi:10.1189/jlb.0205061

[46] Shojaei, F., Singh, M., Thompson, J.D. and Ferrara, N. (2008) Role of bv8 in neutrophil dependent angiogenesis in a transgenic model of cancer progression. Proceedings of the National Academy of Sciences of the United States of America, 105, 2675-2684. doi:10.1073/pnas.0712185105 
[47] Zhong, C., Qu, X., Tan, M., Meng, Y.G. and Ferrara, N. (2009) Characterization and regulation of bv8 in human blood cells. Clinical Cancer Research, 15, 2675-2684. doi:10.1158/1078-0432.CCR-08-1954

[48] Denison, F.C., Battersby, S., King, A.E., Szuber, M. and Jabbour, H.N. (2008) Prokineticin-1 a novel mediator of of the inflammatory response in third trimester human placenta. Endocrinology, 149, 3470-3477. doi:10.1210/en.2007-1695

[49] Bollapragada, S., Youssef, R., Jordan, F., Greer, I., Norman, J. and Nelson, S. (2009) Term labour is associated with core inflammatory response in human fetal membranes, myometrium and cervix. American Journal of Obstetrics and Gynecology, 200, 104. e1-e11.

[50] Gorowiec, M.R., Catalano, R.D., Norman, J.E., Denison, F.C. and Jabbour, H.N. (2011) Prokineticin 1 induces inflammatory response in human myometrium: A Potential role in initiating term and preterm parturition. The American Journal of Pathology, 179, 2709-2719. doi:10.1016/j.ajpath.2011.08.029

[51] Catalano, R.D., Lannagan, T.R.M., Gorowiec, M., Denison, F.C., Norman, J.E. and Jabbour, H.N. (2010) Prokineticins: Novel mediators of inflammatory and contractile pathways at parturition? Molecular Human Reproduction, 16, 311-319. doi:10.1093/molehr/gaq014

[52] Brouillet, S., Hoffmann, P., Benharouga, M., Salomon, A., Schaal, J.P., Feige, J.J. and Alfaidy, N. (2010) Molecular characterization of EG-VEGF-mediated angiogenesis: Differential effects on microvascular and macrovascular endothelial cells. Molecular Biology of Cell, 21, 2832-2843. doi:10.1091/mbc.E10-01-0059

[53] Brouillet, S., Hoffmann, P., Chauvet, S., Salomon, A., Chamboredon, S., Sergent, F., Benharouga, M., Feige, J.J. and Alfaidy, M. (2012) Revisiting the role of hCG: New regulation of the angiogenic factor EG-VEGF and its receptors. Cellular and Molecular Life Sciences, 69, 15371550. doi:10.1007/s00018-011-0889-x

[54] Nugent, J.L., Wareing, M., Palin, V., Sibley, C.P., Baker, P.N., Ray, D.W., Farrow, S.N. and Jones, R.L. (2013) Chronic glucocorticoid exposure potentiates placental chorionic plate artey constriction: Implications for aberrant fetoplacental vascular resistance in fetal growth restriction. Endocrinology, 154, 876-887. doi:10.1210/en.2012-1927

[55] Feflea, S., Maria, A., Cimpean, A.M., Ceausu, R.A., Gaje, P. and Raica, M. (2012) Effects of antibodies to EGVEGF on angiogenesis in the chick embryo chorioallantoic membrane. In Vivo, 26, 793-797.

[56] Jabbour, H.N., Kelly, R.W., Fraser, H.M. and Critchley, H.O. (2006) Endocrine regulation of menstruation. Endocrine Reviews, 27, 17-46.

[57] Shaw, J.L., Oliver, E., Lee, K.F., Entrican, G., Jabbour, H.N., Critchley, H.O. and Horne, A.W. (2010) Cotinine exposure increases fallopian tube PROKR1 expression via nicotinic AchR(alpha)-7: A potential mechanism explaining the link between smoking and tubal ectopic pregnancy. The American Journal of Pathology, 177, 2509-2515. doi:10.2353/ajpath.2010.100243

[58] Shaw, J.L., Wills, G.S., Lee, K.E., Horner, P.J., McClure,
M.O., Abrahams, V.M., Wheelhouse, N., Jabbour, H.N., Critchley, H.O., Entrican, G. and Horne, A.W. (2011) Chlamydia trachomatis infection increases fallopian tube PROKR2 via TLR2 and NFkappaB activation resulting in a microenvironment predisposed to ectopic pregnancy. The American Journal of Pathology, 178, 253-260. doi:10.1016/j.ajpath.2010.11.019

[59] Ji, Y.F., Chen, L.Y., Xu, K.H., Yao, J.F. and Shi, Y.F. (2009) Locally elevated leukemia inhibitory factor in the inflamed fallopian tube resembles that found in tubal pregnancy. Fertility and Sterility, 91, 2308-2314. doi:10.1016/j.fertnstert.2008.01.110

[60] LeCouter, J., Lin, R., Tejada, M., Frantz, G., Peale, F., Hillan, K.J. and Ferrara, N. (2003) The endocrine-glandderived VEGF homologue bv8 promotes angiogenesis in the testis: Localization of bv8 receptors to endothelial cells. Proceedings of the National Academy of Sciences of the United States of America, 100, 2685-2690. doi:10.1073/pnas.0337667100

[61] Wechselnberger, C., Puglisi, R., Engel, E., Lepperdinger, G., Boitani, C. and Kreil, G. (1999) The mammalian homologues of frog bv8 are mainly expressed in spermatocytes. FEBS Letters, 462, 177-181. doi:10.1016/S0014-5793(99)01473-8

[62] Sampson, M., Peale Jr., F.V., Frantz, G., Rioux-Leclercq, N., Rajpert De Meyts, E. and Ferrara, N. (2004) Human endocrine-gland derived vascular endothelial growth factor: Expression early in development and in leydig cell tumors suggests roles in normal and pathological testis angiogenesis. The Journal of Clinical Endocrinology \& Metabolism, 89, 4078-4088. doi:10.1210/jc.2003-032024

[63] Lin, R., LeCouter, J., Kowalski, J. and Ferrara, N. (2002) Characterization of endocrine gland derived vascular endothelial growth factor signaling in adrenal cortex capillary endothelial cells. The Journal of Biological Chemistry, 277, 8724-8729. doi:10.1074/jbc.M110594200

[64] Aston, K.L. and Carrell, D.I. (2009) Genome-wide study of single-nucleotide polymorphisms associated with azoospermia and severe oligozoospermia. Journal of Andrology, 30, 711-725. doi:10.2164/jandrol.109.007971

[65] Tu, L.H., Yu, L.L., Xiong, C.L. and Zhang, H.P. (2012) Potential role of prokineticin 2 in experimental varicocoele-induced rat testes. Urology, 80, 952.e15-e19.

[66] Pasquali, D., Rossi, V., Staibano, S., DeRosa, G., Chieffi, P., Prezioso, D., Mirone, V., Mascolo, M., Tramantano, D., Bellastella, A. and Sinisi, A.A. (2006) The endocrine gland-derived vascular endothelial growth factor (EGVEGF/prokineticin 1 and 2 and receptor expression in human prostate: Upregulation of EG-VEGF/prokineticin 1 with malignancy. Endocrinology, 147, 4245-4251. doi:10.1210/en.2006-0614

[67] De la Iglesia, H.O. and Schwaerz, W.J. (2006) Minireview: Timely ovulation: Circadian regulation if the femalehypothalamo-pituitary-gonadalaxis. Endocrinology, 2147, 1148-1153.

[68] Ward, D.R., Dear, F.M., Ward, J.A., Anderson, S.I., Spergel, D.J., Smith, P.A. and Ebling, F.J. (2009) Innervation of gonadotropin-releasing hormones neurons by peptidergic neurons conveying circadian or energy bal- 
ance information in the mouse. PLoS One, 4, e5.322.

[69] Pitteloud, N., Zhang, C., Pognatelli, D., Li, J.D., Raivio, T., Cole, L.W., Plumer, L.W., Jacobson-Dickman, E.E., Mellon, P.L., Zhou, Q.Y. and Crowley Jr., W.F. (2007) Loss of function mutation in the prokineticin 2 gene causes Kallmann syndrome and normosmic idiopathic hypogonadotropic hypogonadism. Proceedings of the $\mathrm{Na}$ tional Academy of Sciences of the United States of America, 104, 17447-17452. doi:10.1073/pnas.0707173104

[70] Matsumoto, S., Yamazaki, C., Masumoto, K.H., Nagano, M., Naito, M., Soga, T., Hiyama, H., Matsumoto, M., Tkasaki, J., Kamohara, M., Matsuo, A., Ishii, H., Kabori, M., et al. (2006) Abnormal development of the olfactory bulb and reproductive system in mice lacking prokineticin receptor PKR2. Proceedings of the National Academy of Sciences of the United States of America, 103, 4140-4145. doi:10.1073/pnas.0508881103

[71] Martin, C., Balasubramanium, R., Dwyer, A.A., Au, M.G., Sidis, Y., Kaiser, U.B., Seminara, S.B., Pitteloud, N., Zhou, Q.Y. and Crowley Jr., W.F. (2011) The role of the prokineticin 2 pathway in human reproduction: Evidence from the study of human and murine mutations. Endocrine Reviews, 32, 225-246. doi:10.1210/er.2010-0007

[72] Dode, C., Teixeira, L., Levvilliers, J., Fouveaut, C., Bouchard, P., Kottler, M.L., Lespinasse, J., LienhartRoussie, A., Mathew, M., Mierman, A., et al. (2006) Kalmann syndrome: Mutations in the genes encoding prokineticin 2 and prokineticin receptor 2. PLoS Gene, 2, e175.

[73] Cole, L.W., Sidis, Y., Zhang, C., Quinton, R., Plummer, L., Pignarelli, D., Hughes, V.A., Dwyer, A.A., Raivio, T., Hayes, F.J., Seminara, S.B., Huot, C., Alos, N., Speiser, P., Takeshita, A., et al. (2008) Mutations in prokineticin2 and prokineticin receptor genes in human gonadotrophin-releasing hormone deficiency: Molecular genetics and clinical spectrum. The Journal of Clinical Endocrinology \& Metabolism, 93, 3551-3559. doi: $10.1210 /$ jc. $2007-2654$

[74] Leroy, C., Fouveaut, C., Leclercq, S., Jacquemont, S., Boullay, H.D., Lespinasse, J., Delpech, M., Dupont, J.M., Hardelin, J.P. and Dode, C. (2008) Biallelic mutations in the prokineticin gene in two sporadic case of Kallmann syndrome. European Journal of Human Genetics, 16, 865-868. doi:10.1038/ejhg.2008.15

[75] Sinisi, A.A., Asci, R., Bellastella, G., Maione, L., Esposito, D., Elefante, A., DeBellis, A., Bellastella, A. and Iolascon, A. (2008) Homozygous mutation in the prokineticin receptor 2 gene (Val 274Asp) presenting as reversible Kallmann syndrome and persistent oligozoospermia: Case report. Human Reproduction, 23, 23802384. doi:10.1093/humrep/den247

[76] Abreu, A.P., Trarbach, E.B., de Castro, M., Frade-Costa, E.M., Versiani, B., Matias-Baptista, M.T., Garmes, H.M., Mendonca, B.B. and Latronico, A.C. (2008) Loss of function mutations in the genes encoding prokineticin 2 or prokineticin receptor 2 cause autosomal recessive Kallmann syndrome. The Journal of Clinical Endocrinology \& Metabolism, 93, 4113-4118. doi:10.1210/jc.2008-0958
[77] Canto, P.M., Munguia, P., Soderlund, D., Castro, J.J. and Mendez, J.P. (2009) Genetic analysis in patients with Kallmann syndrome: Coexisrence of mutations prokineticin receptor 2 and KAL1. Journal of Andrology, 30, 41-45. doi:10.2164/jandrol.108.005314

[78] Sarfati, J., Guiochon-Mantel, A., Rondard, P., Arnulf, L., Garcio-Pinero, A., Wolczynski, S., Brailly-Tabard, S., Bidet, M., Ramos-Arroyo, M., Mathieu, M., LienhardtRoussie, A., Morgan, G., et al. (2010) A comparative phenotypic study of Kallmann syndrome patients carrying monoallelic and biallelic mutations in the prokineticin 2 or prokineticin receptor 2 genes. The Journal of Clinical Endocrinology \& Metabolism, 85, 659-669. doi:10.1210/jc.2009-0843

[79] Monnier, C., Dode, C., Fabre, L., Teixeira, L., Labesse, G., Pin, J.P., Hardelin, J.P. and Rondard, P. (2009) PROKR2 missense mutations associated with Kallmann syndrome impair receptor signaling activity. Human Molecular Genetics, 18, 75-81. doi:10.1093/hmg/ddn318

[80] Balasubramaniam, R., Plummer, L., Sidis, Y., Pitteloud, N., Cecila, N., Zhou, Q.Y. and Crowley Jr., W.F. (2011) The puzzles of the prokineticin 2 pathway in human reproduction. Molecular and Cellular Endocrinology, 346, 44-50. doi:10.1016/j.mce.2011.05.040

[81] Plana, A.M., Villanueva, C., Laccourreye, O., Bonfils, P. and de Roux, N. (2013) PROKR2 and PROK2 mutations cause isolated congenital anosmia without gonadotropic deficiency. European Journal of Endocrinology, 168, 3137. doi:10.1530/EJE-12-0578

[82] Lewkowitz-Shupntoff, H.M., Hughes, V.A., Plummer, L., Au, M.G., Doty, R.L., Seminara, S.B., Chan, Y.M., Potteloud, N., Crowley Jr., W.F. and Balasubramaniam, R. (2012) Olfactory phenotypic spectrums in idiopathic hypogonadotropic hypogonadism: Pathophysiological and genetic implications. The Journal of Clinical Endocrinology \& Metabolism, 97, E136-E144.

doi:10.1210/jc.2011-2041

[83] Hardelin, J.P. and Dode, C. (2008) The complex genetics of Kallmann syndrome: KAL1, FGFR1, FGF8, PROKR2, PROK2, et al. Sexual Development, 2, 181-193. doi:10.1159/000152034

[84] Chan, Y.M., De Guillebon, A., Lang-Muritano, M., Plummer, L., Cerrato, F., Tsiaras, S., Gaspert, A., Lavoie, H.B., Crowley Jr., W.F., Amory, K., Pitelloud, N. and Seminara, S.B. (2009) GNRH1 mutations in patients with idiopathic hypogonadotropic hypogonadism. Proceedings of the National Academy of Sciences of the United States of America, 106, 11703-11708. doi:10.1073/pnas.0903449106

[85] Peng, Z., Tang, Y., Luo, H., Jiang, F., Sun, L. and Li, J.D. (2011) Disease causing mutation in PKR2 receptor reveals a critical role of positive charges in the second intracellular loop for G-protein coupling and receptor trafficking. The Journal of Biological Chemistry, 286 , 16615-16622. doi:10.1074/jbc.M111.223784

[86] Abreu, A.P., Noel, S.D., Xu, S., Carroll, R.S., Ltronico, A.C. and Kaiser, U.B. (2012) Evidence of the first intracellular loop of prokineticin receptor 2 in receptor function. Molecular Endocrinology, 26, 1417-1427. doi:10.1210/me.2012-1102 
[87] Abreu, A.P., Kaiser, U.B. and Latronico, A.C. (2010) The role of prokineticins in the pathogenesis of hypogonado tropic hypogonadism. Neuroendocrinology, 91, 81-90. doi: $10.1159 / 000308880$

[88] Kishi, T., Kitajima, T., Tsunoka, T., Okumura, T., Ikeda, M., Okochi, T., Kinoshita, Y., Kawashima, K., Yamanouchi, Y., Ozaki, N. and Iwara, N. (2009) Possible association of prokineticin receptor 2 gene (PROKR2) with mood disorders in the Japanese population. Neuromolecular Medicine, 11, 114-122.

[89] Caronia, L.M., Martin, C., Welt, K.C., Sykiotis, G.P., Quinton, R., Thambundit, A., Avbelj, M., Dhruvakumar, S., Plummer-Hughes, V.A., Seminara, S.B., et al. (2011) A genetic basis for functional hypothalamic amenorrhea. The New England Journal of Medicine, 364, 215-225. doi:10.1056/NEJMoa0911064

[90] Reynaud, R., Jayakody, S.A., Monnier, C., Saveanu, A., Bouligand, J., Guedj, A.M., Simonin, G., Lecomte, M., Barlier, A., Rondard, P., Martinez-Barbera, J.P., Guiochon-Mantel, A. and Brue, T. (2012) PROKR2 variants in multiple hypopituitarism with pituitary stalk interrupttion. The Journal of Clinical Endocirnology \& Metabolism, 97, E1068-E1073. doi:10.1210/jc.2011-3056

[91] McCabe, M.J., Gaston-Massuet, C., Gregory, L.C., Alatzoglu, K.S., Tziaferi, V., Sbai, O., Rondard, P., Masumoto, K.H., Nagano, M., Shigeyoshi, Y., Pfiefer, M., Hulse, T., Buchanan, C.R., Potteloud, N., Martinez-Bar- bera, J.P. and Dattani, M.T. (2013) Variations in PROKR2 but not PROK2, are associated with hypopituitarism and septo-optic dysplasia. The Journal of Clinical Endocirnology \& Metabolism, 98, E547-E557.

[92] Raica, M., Coculescu, M., Cimpean, M. and Ribatti, D. (2010) Endocrine gland derived-VEGF is downregulated in human pituitary adenoma. Anticancer Research, 30, 3981-3986.

[93] Levit, A., Yarnitzky, T., Wiener, A., Meidan, R. and Niv, M.Y. (2011) Modeling of human prokineticin receptors: Interactions with novel small molecules binders and potential off-target drugs. PLoS One, 6, e27990.1-17.

[94] Alvarez, C., Alonso-Muriel, I., Garcia, G., Crespo, J., Bellever, J., Simon, C. and Pellicer, A. (2007) Implantation is apparently unaffected by the dopamine agonist Cabergoline when administered to prevent ovarian hyperstimulation syndrome in women undergoing assisted reproduction treatment: A pilot study. Human Reproduction, 22, 3210-3214. doi:10.1093/humrep/dem315

[95] Sykiotis, G.P., Plummer, L., Hughes, V.A., Au, M., Durrani, S., Young, S.N., Dwyer, A.A., Quinton, R., Hall, J.E., Gusella, J.F., Seminara, S.B., Crowley Jr., W.F. and Pitteloud, N. (2010) Oligogenic basis of isolated gonadotropin-releasing hormone deficiency. Proceedings of the National Academy of Sciences of the United States of America, 107, 15140-15144. doi:10.1073/pnas.1009622107 